\title{
PERFORMANCE OF DIFFERENT CREEP MODELS IN THE ANALYSIS OF FIRE EXPOSED STEEL MEMBERS
}

\author{
Neno Torića ${ }^{\text {, Rui Rui Sun }}{ }^{\mathrm{b}}$, Ian W. Burgess ${ }^{\mathrm{c}}$ \\ ${ }^{a}$ University of Split, Faculty of Civil Engineering, Architecture and Geodesy, Split, Croatia \\ ${ }^{\mathrm{b}}$ MMI Engineering, Aberdeen, UK \\ ${ }^{c}$ University of Sheffield, Department of Civil and Structural Engineering, Sheffield, UK
}

\begin{abstract}
In order to model the impact of the creep strains on the behaviour of steel in fire, several creep models have been implemented into Vulcan research code. The paper presents verifications of these creep models for fire-exposed steel against transient fire tests of simply supported steel beams with various loading arrangements, including bending combined with axial compression. In addition, a creep-free analysis of the fire tests has been performed using a newly developed creep-free methodology. Creep-free analysis is vital in explicit modelling of steel creep in fire, since most of the available material models of steel in fire were derived from transient coupon tests and inherently included creep associated with the particular heating rates used in the tests.
\end{abstract}

Keywords: Fire, finite element, steel, creep, creep-free

\section{INTRODUCTION}

A limited amount of research is currently available on the effects of creep on steel structures exposed to fire. The most probable reason for the researchers' disinterest in the creep strain in fire was the standardized fire test (ASTM, 2005, ISO834, 1975) of isolated steel members or subassemblies, which essentially imposes high heating rates onto the steel. Since the development of creep strain is closely related to the duration of fire exposure, the creep strains would not be pronounced in standard fire tests. Additionally, stress-strain models including creep in an implicit manner, such as the Eurocode 3 (EN1993-1-2, 2005) model, have so far generally been considered a viable solution to the creep problem. The Eurocode 3 material model is widely adopted in performance-based structural fire engineering across Europe and in scientific research worldwide.

As a phenomenon, creep development under stationary heating regimes has been investigated rather well during the course of the twentieth century. Research on creep development under various temperatures and stress levels has revealed three distinctive phases of change of creep strain rate: the primary, secondary and tertiary creep phases. It has been pointed out that the exposure duration and the stress and temperature levels all have significant influences on the creep strain in fire. The higher stress and temperature levels can accelerate the evolution of creep strain, which can have a negative effect on structures' failure mechanisms.

Creep analysis in general is a vital part of structural fire analysis, because high-temperature creep greatly affects the steel behaviour at the very slow heating rates (Toric et al. 2013, Morovat et al. 2014), which may occur in both protected and unprotected steel members during the course of a fire. Various phenomenological creep models have been developed so far, but none of these seems to be designed for universal application in structural fire analysis. This shortcoming is related to the restrictive nature of the material creep properties derived from isolated test studies.

Additionally, the implicit nature of the widely used stress-strain models, such as the Eurocode 3 model, makes creep analysis more difficult, since even the analysis without explicit creep consideration contains inaccuracies in predicting structural behaviour in the early stages of the analysis.

This paper aims to explore the accuracy of a selected number of creep models in predicting the behaviour of simply supported steel beams in transient fire tests with various loading arrangements, 
including combined bending and axial compression (Boko et al. 2012). Three creep models for fireexposed steel have been implemented in the Vulcan research code, which is used for the structural fire analysis within this study.

Additional consideration in the paper is given to the development of a 'creep-free' material model, which is constructed on the same basis as the Eurocode 3 material model. The creep-free material model is necessary in order to conduct a proper explicit-creep analysis. Discussions regarding the influence of implicit creep embodied in Eurocode 3 and the performance of selected creep models are also presented, based on a comparison between the results from creep modelling and fire tests.

\section{CREEP MODELLING}

Three different creep models were used in the analyses, including: $C r_{-} 1$ - Harmathy's (1976) strain hardening model, $C r \_2$ - Harmathy's (1967) time hardening model and $C r_{-} 3$ - Plem's (1975) strain hardening model. A brief introduction to the creep model implementation is given in this section.

The selected creep models cover a range of rules based on strain and time hardening, in order to take into account possible changes in the stress level.

Harmathy's strain hardening rule can be expressed as:

$$
\varepsilon_{c r}=Z \cdot \exp \left(-\frac{\Delta H}{R \cdot T_{\mathrm{R}}}\right) \cdot \operatorname{coth}^{2}\left(\frac{\varepsilon_{\mathrm{cr}, \mathrm{c}}}{\varepsilon_{\mathrm{cr}, 0}}\right) \cdot \Delta t
$$

in which $T_{\mathrm{R}}$ is the temperature $(\mathrm{K}), R$ is the universal gas constant $(\mathrm{J} / \mathrm{molK}), \Delta H$ is the creep activation energy $(\mathrm{J} / \mathrm{mol}), Z$ is the Zener-Hollomon parameter $\left(\mathrm{h}^{-1}\right), \varepsilon_{\mathrm{cr}, 0}$ is a dimensionless creep parameter, $\varepsilon_{\mathrm{cr}, \mathrm{c}}$ is the previously accumulated creep strain and $\Delta t$ is the time increment $(\mathrm{h})$.

The second creep model implemented follows Harmathy's a time hardening rule, which can be expressed as:

$$
\begin{array}{cc}
\varepsilon_{\mathrm{cr}}=\frac{\varepsilon_{\mathrm{cr}, 0}}{\ln 2} \cdot \cosh ^{-1}\left(2^{\frac{z \theta}{\varepsilon_{\mathrm{cr}, 0}}}\right) & \left(\theta<\theta_{0}\right) \\
\varepsilon_{\mathrm{cr}}=\varepsilon_{\mathrm{cr}, 0}+\mathrm{Z} \theta & \left(\theta \geq \theta_{0}\right) \\
\theta_{0}=\varepsilon_{\mathrm{cr}, 0} / \mathrm{Z} &
\end{array}
$$

The third creep model implemented follows Plem's strain hardening rule, which can be expressed as:

$$
\begin{array}{cc}
\varepsilon_{\mathrm{cr}}=\varepsilon_{\mathrm{cr}, 0}\left(2 \sqrt{\mathrm{Z} \theta / \varepsilon_{\mathrm{cr}, 0}}\right) & \left(0 \leq \theta<\theta_{0}\right) \\
\varepsilon_{\mathrm{cr}}=\varepsilon_{\mathrm{cr}, 0}+\mathrm{Z} \theta \quad\left(\theta \geq \theta_{0}\right)
\end{array}
$$

in which $\theta_{0}$ is determined from Eqn (4) and $\theta$ is temperature compensated time (Harmathy, 1976). The inclusion of creep strain into structural modelling is achieved through explicit consideration by adding the creep term in the total strain equation:

$$
\varepsilon_{\mathrm{tot}}=\varepsilon_{\mathrm{th}}(T)+\varepsilon_{\sigma}(\sigma, T)+\varepsilon_{\mathrm{cr}}(\sigma, T, t)
$$

in which $\varepsilon_{\text {tot }}$ is the total strain, $\varepsilon_{\text {th }}(T)$ is the thermal strain and $\varepsilon_{\sigma}(\sigma, T)$ is the stress-related strain. The strain $\varepsilon_{\text {cr }}(\sigma, T, t)$ is the stress-, temperature- and time-dependent creep strain. Creep parameters from the study by Harmathy and Stanzak (1970) were chosen for the analysis, since they are based on a steel grade with yield strength close to the standard Eurocode grade S275. 


\section{THE CREEP-FREE CONCEPT}

The basic methodology of removing implicit creep from the Eurocode 3 material model revolves around finding postulated implicit creep values from transient coupon tests used as the background to creation of the Eurocode 3 steel material model (Kirby and Preston, 1988).

Since the test data published by Kirby and Preston provided total strain (the sum of stress-related and creep strains), the only natural way of removing creep strain is to apply the explicit creep models to determine the postulated implicit creep value, and then to subtract it from the total strain value. This is practically achievable by creating a postulated implicit creep function and in sequence excluding it from the total strain. The creep-free analysis procedure (Torić et al. 2014) is divided into three steps:

1. Conducting explicit creep analyses for a set of transient coupon simulations at different stress levels and at a predefined heating rate (stress interval in the range 25-50 MPa).

2. Extraction of a set of creep strain-temperature curves from the transient coupon simulations of Step 1.

3. Creation of a set of temperature-dependent stress-creep strain curves from the creep straintemperature curves from Step 2. The curves from Step 3 represent the postulated implicit creep functions which can then be used to subtract implicit creep from the total strain.

The projected implicit creep value is determined as a function of stress and temperature, in order to exclude the implicit creep content from transient structural fire analysis. The postulated implicit creep function (denoted $\varepsilon_{\text {impl,cr }}(\sigma, T)$ ) is then incorporated as the fourth term in Equation (7):

$$
\varepsilon_{\mathrm{tot}}=\varepsilon_{\mathrm{th}}(T)+\varepsilon_{\sigma}(\sigma, T)+\varepsilon_{\mathrm{cr}}(\sigma, T, t)-\varepsilon_{\mathrm{impl}, \mathrm{cr}}(\sigma, T)
$$

Comparison of the creep-free analysis and analysis using the implicit Eurocode 3 material model (marked as 'skeleton') is presented in Figure 1.

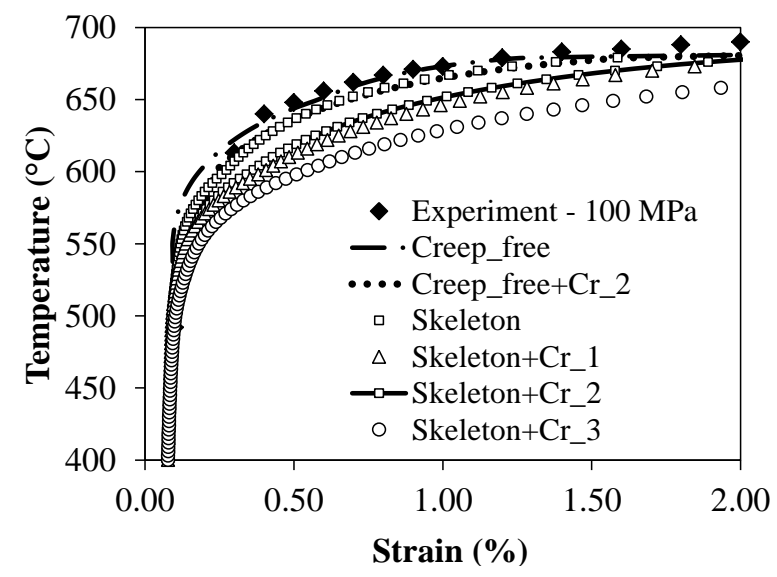

Fig. 1 Application of creep-free analysis and comparison with transient test results at $100 \mathrm{MPa}$ from Kirby and Preston (1988) for heating rate $10^{\circ} \mathrm{C} / \mathrm{min}-$ steel S355.

\section{NUMERICAL MODELLING}

Two fire tests from Boko's (2012) study were chosen to test the performance of the selected creep models in predicting the creep behaviour of beams during fire exposure. Figure 2 presents the structural model and the finite element mesh used for modelling the fire tests. The selected tests refer to a combined bending and compressive force test with the following test parameters: M1: $\mathrm{V} / \mathrm{H}=400 / 200 \mathrm{kN}$ and $\mathrm{M} 2: \mathrm{V} / \mathrm{H}=400 / 250 \mathrm{kN}$. Heating curves for the upper and lower flanges of the beam at mid-span for both tests are presented in Figure 3. Since the beam was partially heated over its span, seven different temperature curves were used to take the effect of this partial heating into account. The temperature curves and their association with the finite element modelling are provided in one of the COST TU0904 publications (Torić and Burgess, 2014). Table 1 summarizes 
the parameters of the selected tests, and Figure 4 presents the simulation results using different creep and stress-strain models (creep-free Eurocode 3 and implicit Eurocode 3).
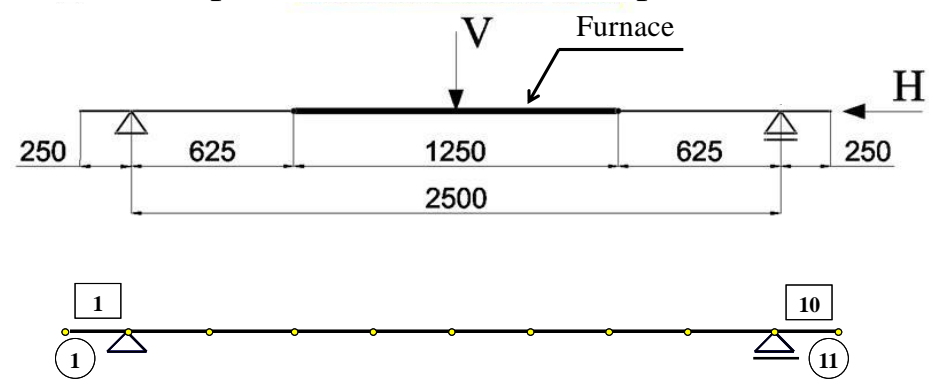

Fig. 2 Structural model and finite element mesh.
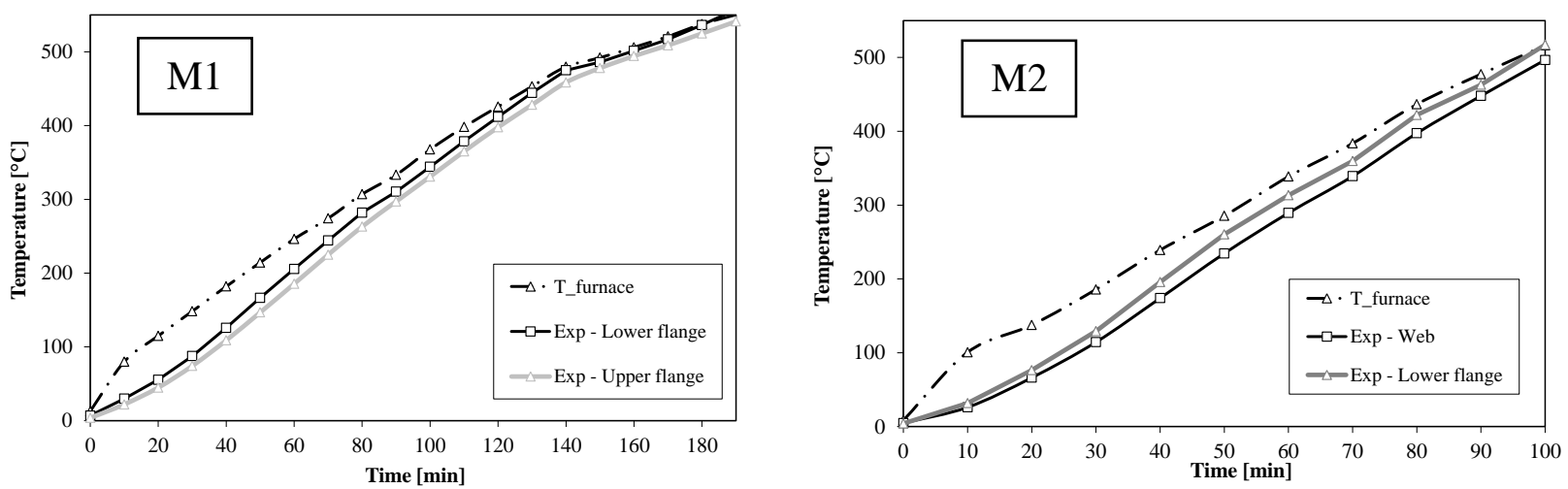

Fig. 3 Heating curves for selected tests.
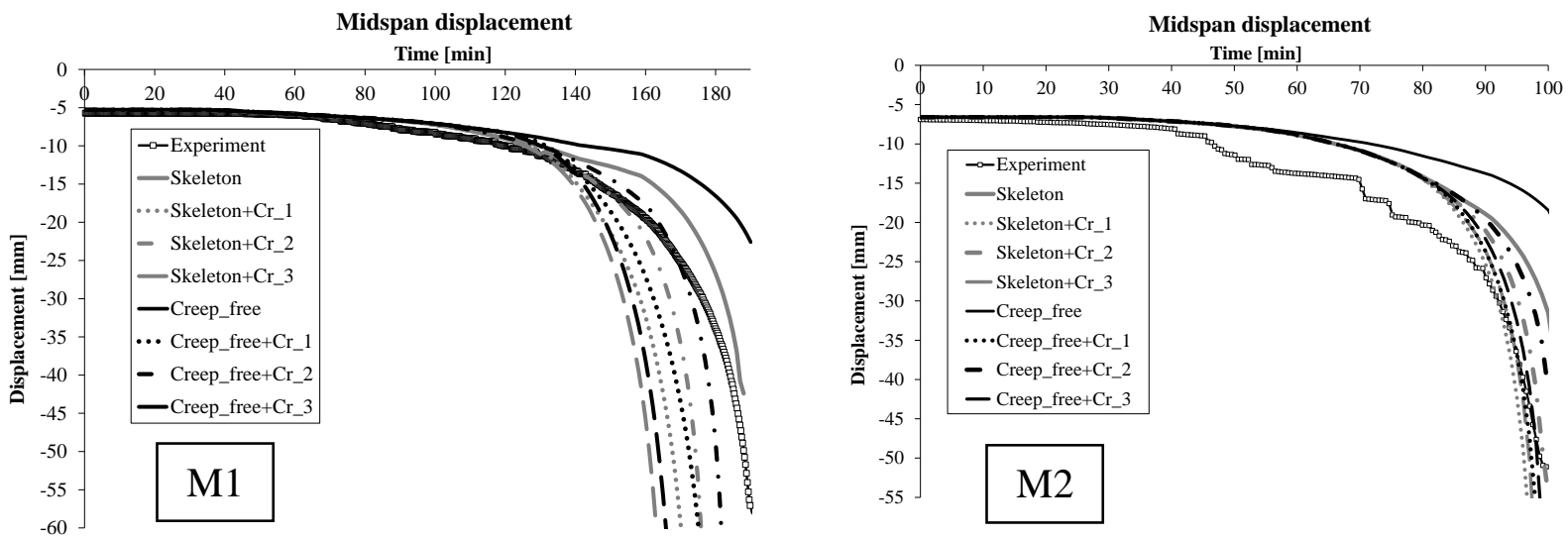

Fig. 4 Application of creep-free analysis and comparison with test results using selected creep models.

Table 1 Key parameters of the tests.

\begin{tabular}{|c|c|c|c|}
\hline \multicolumn{2}{|c|}{ Testing method } & \multicolumn{2}{|c|}{ Transient } \\
\hline \multicolumn{2}{|c|}{ Load type } & \multicolumn{2}{|c|}{ Bending + axial force } \\
\hline \multicolumn{2}{|c|}{ Member (Steel S355) } & M1 & M2 \\
\hline \multicolumn{2}{|c|}{ Test time (min) } & 190 & 100 \\
\hline \multirow{2}{*}{$\begin{array}{l}\text { Force } \\
(\mathrm{kN})\end{array}$} & Axial $(\mathrm{kN})$ & 400 & 400 \\
\hline & Vertical $(\mathrm{kN})$ & 200 & 250 \\
\hline
\end{tabular}




\section{DISCUSSION OF RESULTS}

The average heating rate used in the fire tests was approximately $3.5^{\circ} \mathrm{C} / \mathrm{min}$ for member $\mathrm{M} 1$, and approximately $5^{\circ} \mathrm{C} / \mathrm{min}$ for member $\mathrm{M} 2$. Comparison of the results from the creep-free analysis with implicit-creep analysis (marked as 'skeleton') without explicit creep consideration indicates that there are significant discrepancies in the deflection responses of the selected steel beams using different creep models.

The large differences in predicted deflections can be attributed to the substantial influence of implicit creep on the value of tangent modulus of elasticity. This influence is obviously more pronounced in the presence of axial compressive force. The limited safety margin in the Eurocode 3 implicit-creep stress-strain law is based on the comparison between the explicit creep (creep-free model with explicit creep strain) simulations and the implicit creep (Eurocode 3 model) simulation. An earlier beam failure time is observed in the implicit creep analysis. For member M1 this failure time is approximately 5 minutes earlier than that predicted by the creep-free analysis.

It can be seen that the three different creep models provide a reasonable range of deflection predictions for both test cases. Due to the presence of a large axial force in M2, the difference in deflection predictions from the three explicit creep models is less pronounced than that for member M1, which experienced a lower heating rate.

\section{CONCLUSIONS}

Simulation results have shown that all three creep models are capable of reproducing the creep strain evolution in the selected fire tests with sufficient accuracy. The results have also pointed to the limited safety margin in the Eurocode 3 implicit-creep stress-strain law. As a standalone model, Eurocode 3 has a limited capacity to accommodate a sufficient level of creep strain in the fire tests. Even when combined with the explicit creep model, the safety margin of an implicit stress-strain law in predicting the creep strain is relatively low. This postulate is supported by the comparison of explicit creep analysis results using implicit type and creep-free stress-strain model. The difference in failure time predictions between the two approaches is very small, due to presence of axial compressive force in the beam which reduces the importance of the creep strain. Simulation results have also demonstrated that the Eurocode 3 stress-strain model has its limitations in predicting creep effects if heating rates less than $10^{\circ} \mathrm{C} / \mathrm{min}$ are expected. Further analysis is planned using other tested steel members from Boko's study to test the performance of the selected creep models.

\section{ACKNOWLEDGMENT}

The Principal author would like to thank the University of Split, Faculty of Civil Engineering, Architecture and Geodesy for their ongoing financial support.

\section{REFERENCES}

ASTM, 2005. Standard methods of fire tests of building construction and materials (ASTM Standard E11905), American Society for Testing and Materials, West Conshohocken, PA.

Boko, I., Torić, N., Peroš, B. 2012. Structural fire design parameters and procedures - analysis of the potential of Eurocode 3. Materialwissenschaft und Werkstofftechnik, 43(12), p. 1036-1052.

EN 1993-1-2:2005, 2005. Eurocode 3 - Design of steel structures - Part 1-2: General Rules - Structural fire design, European Committee for Standardization, Brussels

Harmathy, T. Z. 1976. Creep deflections of metal beams in transient heating processes with particular reference to fire. Canadian Journal of Civil Engineering, 3(2), p. 219-228.

Harmathy, T. Z. 1967. A comprehensive creep model. Journal of Basic Engineering, 89(3), p. 496-502.

Harmathy, T. Z., Stanzak, W.W. 1970. Elevated-temperature tensile and creep properties of some structural and prestressing steels, National Research Council of Canada, Division of Building Research, Ottawa

ISO 834, 1975. Fire Resistance Tests - Elements of Building Construction, International Organization for Standardization, Switzerland.

Kirby, B. R., Preston, R. R. 1988. High temperature properties of hot-rolled Structural steels for use in fire engineering design studies, Fire Safety Journal, 13, p. 27-37. 
Morovat, M. A., Engelhardt, M. D., Helwig, T. A., Taleff, E. M. 2014. High-temperature creep buckling phenomenon of steel columns subjected to fire. Journal of Structural Fire Engineering, 5(3), p. 189-202.

Plem, E. 1975. Theoretical and Experimental Investigations of Point Set Structures, Swedish Council for Building Research, Document, D9

Torić N., Harapin A., Boko I. 2013. Experimental verification of a newly developed implicit creep model for steel structures exposed to fire. Engineering Structures, 57, p. 116-124.

Torić, N., Sun, R. R., Burgess, I. W. 2014. Testing the acceptability of different creep strain calculation models in structural fire analysis, $8^{\text {th }}$ International Conference on Structures in Fire, 11-13 June Shanghai, China, p. 895-902.

Torić, N., Burgess, I. W. 2014. Benchmark studies for partially heated steel beams, Benchmark studies: Experimental validation of numerical models in fire engineering, CTU Publishing house, CTU Prague, $\mathrm{p}$. 09-20. 